\title{
OPEN Comparative thermal research on tetraazapentalene-derived heat-resistant energetic structures
}

\author{
Jing Zhou ${ }^{1}$, Li Ding ${ }^{1 凶}$, Yong Zhu ${ }^{1}$, Bozhou Wang ${ }^{1 \bowtie}$, Xiangzhi Li ${ }^{1}$ \& Junlin Zhang ${ }^{1,2 \bowtie}$
}

Organic inner salt structures are ideal backbones for heat-resistant energetic materials and systematic studies towards the thermal properties of energetic organic inner salt structures are crucial to their applications. Herein, we report a comparative thermal research of two energetic organic inner salts with different tetraazapentalene backbones. Detailed thermal decomposition behaviors and kinetics were investigated through differential scanning calorimetry and thermogravimetric analysis (DSC-TG) methods, showing that the thermal stability of the inner salts is higher than most of the traditional heat-resistant energetic materials. Further studies towards the thermal decomposition mechanism were carried out through condensed-phase thermolysis/Fourier-transform infrared (in-situ FTIR) spectroscopy and the combination of differential scanning calorimetry-thermogravimetry-mass spectrometry-Fourier-transform infrared spectroscopy (DSC-TG-MS-FTIR) techniques. The experiment and calculation results prove that the arrangement of the inner salt backbones has great influence on the thermal decompositions of the corresponding energetic materials. The weak N4-N5 bond in "y-" pattern tetraazapentalene backbone lead to early decomposition process and the "z-" pattern tetraazapentalene backbone exhibits more concentrated decomposition behaviors.

Research on heat-resistant energetic materials has been intensively conducted worldwide during the past decades. In practice, the improvement of thermal stability is crucial to explosives and propellants working under high temperatures ${ }^{1-3}$. From structural point of view, expansion of the aromatic structures and introduction of amino groups are currently the most efficient strategies to improve the thermal stabilities of energetic materials ${ }^{4,5}$. Such effects are attributed to the additional stabilization effect achieved from the strengthened conjugation and hydrogen bond systems ${ }^{6-9}$. Based on these strategies, a series of energetic structures, such as $2,2^{\prime}, 4,4^{\prime}, 6,6^{\prime}$-hexanitrostilbene $(\mathrm{HNS})^{10}, 2,6$-bis(picrylamino)-3,5-dinitropyridine (PYX $)^{11}, 1,3,5$-triamino-2,4,6-trinitrobenzene $(\mathrm{TATB})^{12}$, and 2,6-diamino-3,5-dinitropyrazine-1-oxide (LLM-105) ${ }^{13}$, have been successfully synthesized and endowed with good thermal stabilities (Fig. 1). However, the number of heat-resistant energetic materials is still highly limited that is difficult to meet the increasingly demanding application requirements.

Salt formation is believed as an alternative approach to improve the thermal stability of energetic materials and this can be illustrated by the comparison of the melting points between $3,3^{\prime}$-diamino- $2,2^{\prime}, 4,4^{\prime}, 6,6^{\prime}$ hexanitrodiphenylamine and its potassium salt ${ }^{14}$ (Fig. 2). However, most salts suffer from severe hygroscopicity which hinders the application of salt formation strategy in heat-resistant energetic materials ${ }^{15,16}$. Different from traditional salt structures, most organic inner salt structures successfully avoid the problems caused by hygroscopicity, making them potential ideal backbones for the synthesis of heat-resistant energetic materials. Despite all these, detailed and systematic research towards the thermal behaviors and pyrolysis mechanism of energetic organic inner salt structures are rarely reported.

Tetraazapentalenes are novel inner salt structures which are ideal for the design of energetic materials and their core nitrogen atoms can be arranged in both " $y-$-" and " $z-$ " patterns ${ }^{17}$. The incorporation of nitro groups into " $y-$ " and "z-" tetraazapentalene backbones have been explored in attempt to synthesize energetic structures (TACOT) with impressive thermal stabilities ${ }^{18-21}$. Further nucleophilic displacement of the $o$-nitro groups in TACOT with azide anion followed by nitration and heating will lead to the formations of similar energetic structures of $\mathrm{DBBD}^{22,23}$ (Fig. 3).

Herein, we focused on a comparative thermal research of two energetic organic inner salts, $y$-PTACOT and $z$-TACOT, which were prepared based on " $y-$ " and " $z$-" tetraazapentalene backbones (Fig. 4). Both experiment and calculation methods are applied to clarify the stabilization effect achieved from the inner salt backbones

\footnotetext{
${ }^{1}$ State Key Laboratory of Fluorine and Nitrogen Chemical, Xi'an Modern Chemistry Research Institute, Xi'an 710065, China. ${ }^{2}$ Department of Chemistry, Technische Universität München, 85748 Garching Bei München, Germany. ${ }^{\boxplus}$ email: dingli403@sina.com; wbz600@163.com; junlin-111@163.com
} 

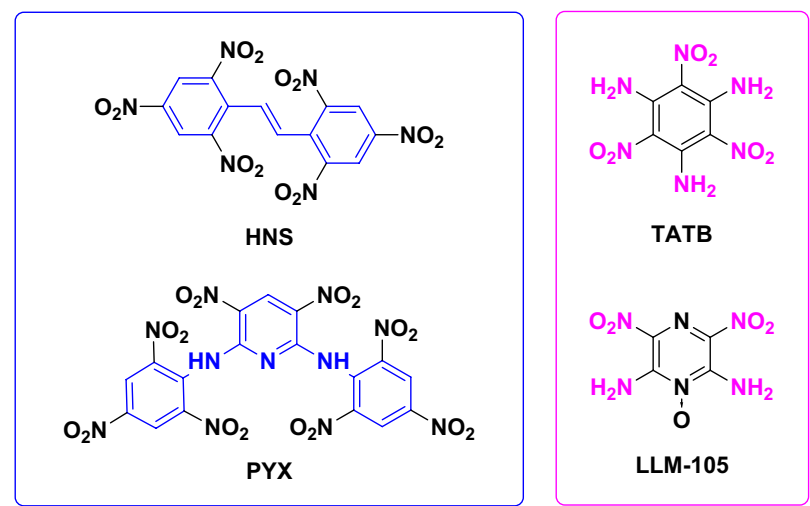

Figure 1. Representative heat-resistant energetic materials.

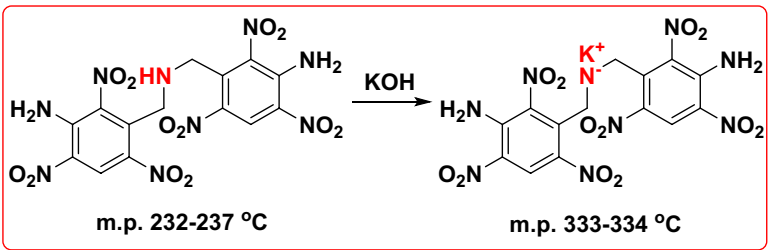

Figure 2. Thermal stability improved by salt formation.<smiles></smiles>
y-PTACOT<smiles></smiles><smiles>O=[N+]([O-])c1cc([N+](=O)[O-])c2c(c1)n1[n-][n+]3c([N+](=O)[O-])cc([N+](=O)[O-])cc3n21</smiles><smiles>O=[N+]([O-])c1cc2c(c([N+](=O)[O-])c1)[N-]c1c([N+](=O)[O-])c([N+](=O)[O-])nc3c1nnn3-2</smiles>

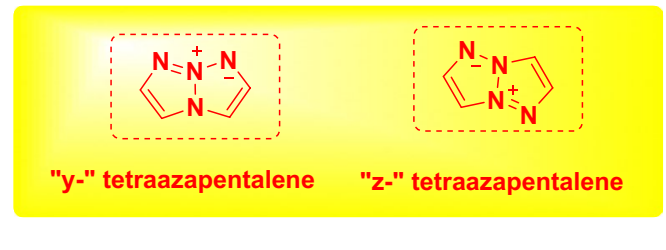<smiles></smiles><smiles></smiles>

Figure 3. Energetic materials based on "y-" and "z-" tetraazapentalene backbones.

and provide further clues to elucidate the pyrolysis mechanisms during the heating process. The comparative studies can also improve the understanding on how the arrangement of the inner salt backbones and elemental composition in the aromatic rings affect their thermal behaviors.

\section{Results and discussion}

Both the backbones of y-PTACOT and z-TACOT are based on tetraazapentalene core structures but arranged in different patterns. As potential heat-resistant energetic materials, the detailed thermal decomposition behaviors were first investigated and compared. As shown in Fig. 5, y-PTACOT and z-TACOT exhibited similar thermal decomposition processes in the range of $0-500^{\circ} \mathrm{C}$. The DSC curve of $y$-PTACOT and z-TACOT at a heating rate of $10{ }^{\circ} \mathrm{C} \mathrm{min}-1$ was consisted of single exothermic decomposition peaks at $409^{\circ} \mathrm{C}$ and $410{ }^{\circ} \mathrm{C}$, respectively, which were much higher than those of most traditional energetic materials. The thermal decompositions of y-PTACOT and $\mathrm{z}$-TACOT were speculated to be one-step reactions with close weight loss data about $64 \%$ and $57 \%$, respectively. However, the heat releasing process of $\mathrm{z}$-TACOT was more concentrated than that of $y$-PTACOT. 


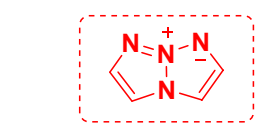

"y-" tetraazapentalene

"z-" tetraazapentalene
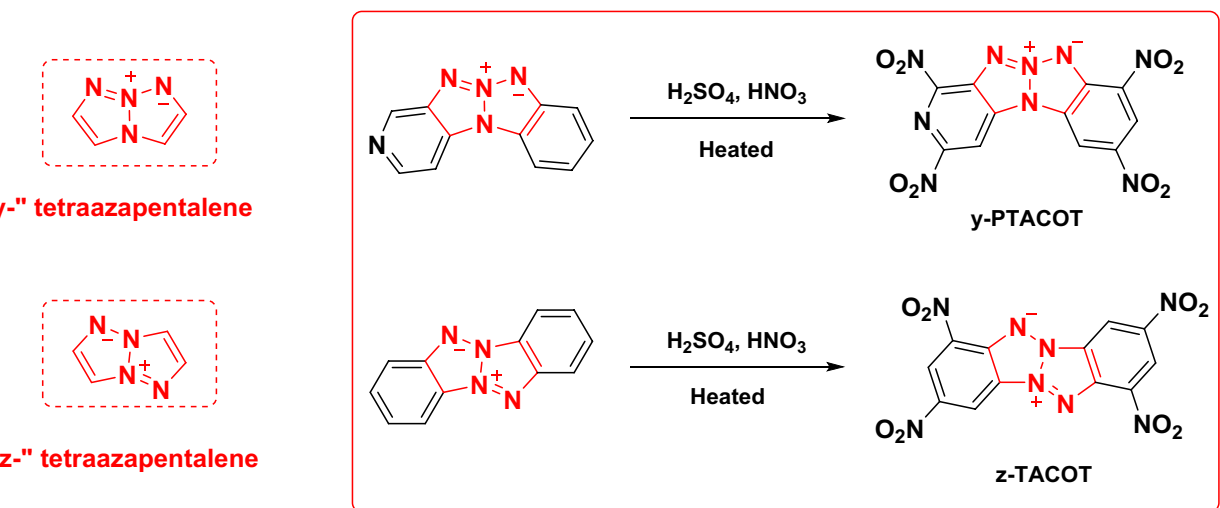

Figure 4. y-PTACOT and $z$-TACOT structures.

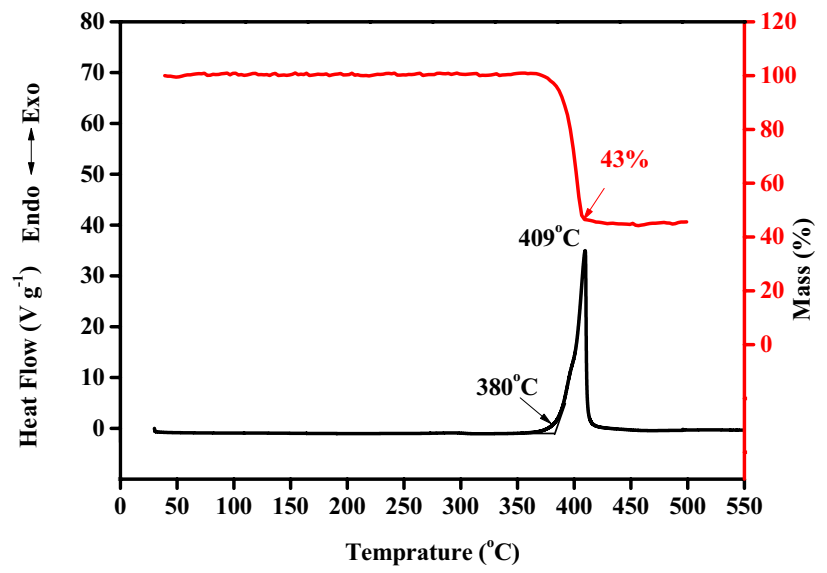

(a)

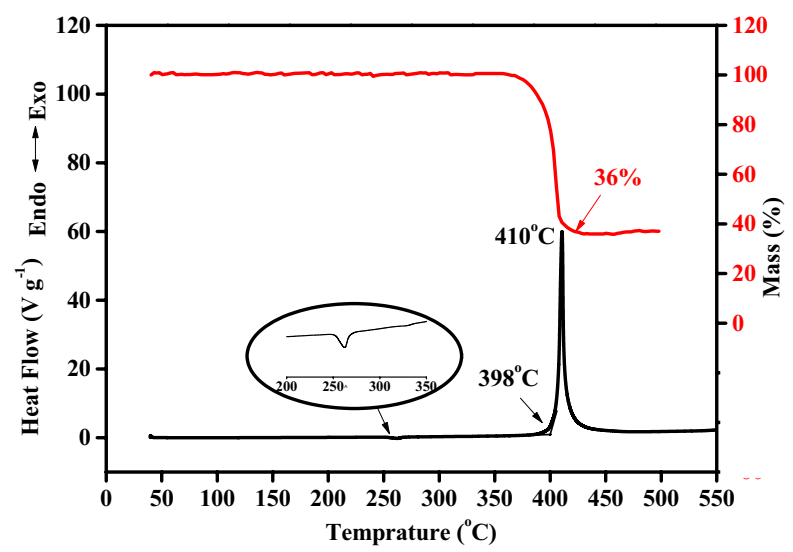

(b)

Figure 5. DSC-TG curves of $\mathrm{y}$-PTACOT (a) and $z$-TACOT (b).

It is noteworthy that a week endothermic peak was observed at about $260^{\circ} \mathrm{C}$ during the decomposition process of $\mathrm{z}$-TACOT with no weight loss, indicating a physical change like melt or crystal transformation. To further investigate this physical change, modulated DSC (MDSC) measurements ${ }^{24}$ of $z$-TACOT were presented. The endothermic peak was only found in the non-reversing heat flows, which means this physical change is irreversible and crystal transformation is the maximum possible process (Fig. 6).

Non-isothermal kinetic studies on thermal decompositions of y-PTACOT and z-TACOT were carried out based on DSC experiments employed at different heating rates (Fig. 7). The thermal decomposition peak and heat release amount for $\mathrm{y}$-PTACOT and $\mathrm{z}$-TACOT at the heating rates of $2,5,10$ and $20^{\circ} \mathrm{C} \mathrm{min}{ }^{-1}$ were summarized in Table 1. It is clear that the decomposition peak shifted towards high temperatures with the increase of heating 


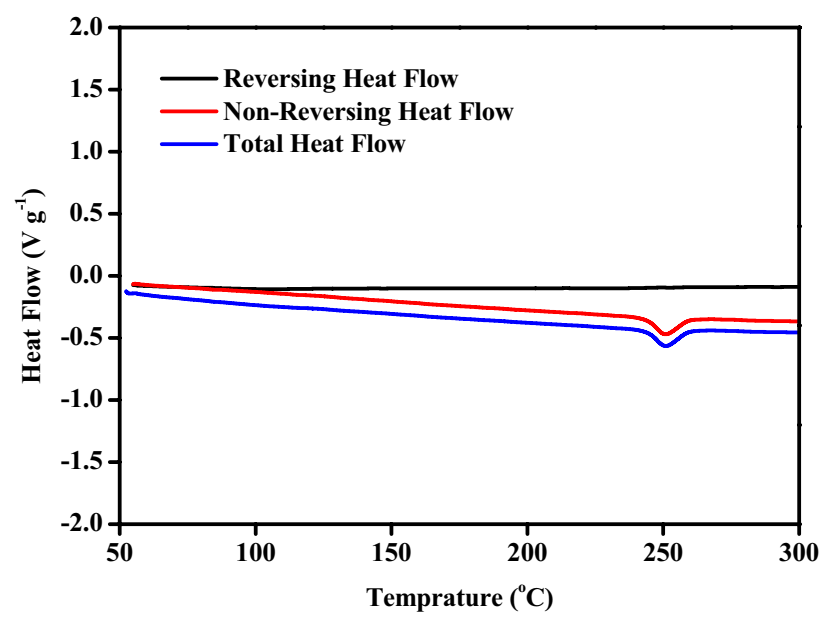

Figure 6. MDSC measurements of z-TACOT.

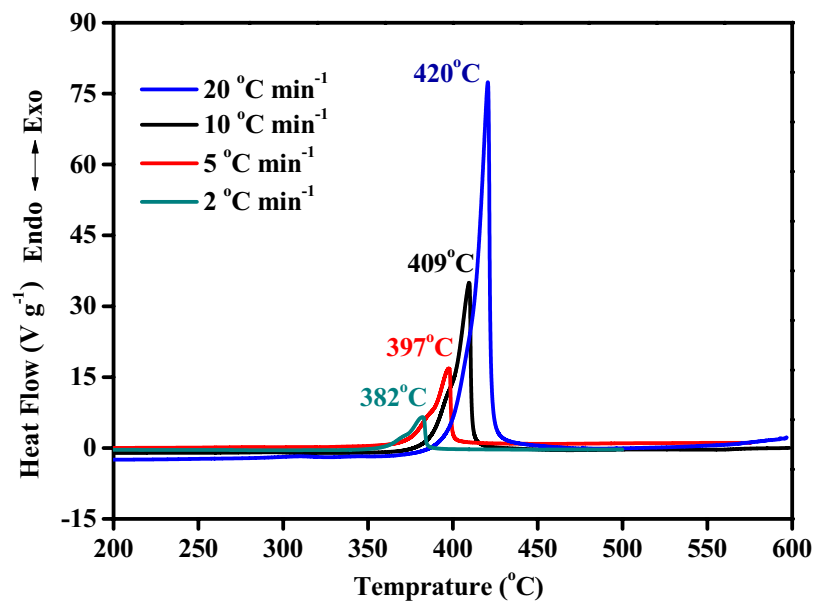

(a)

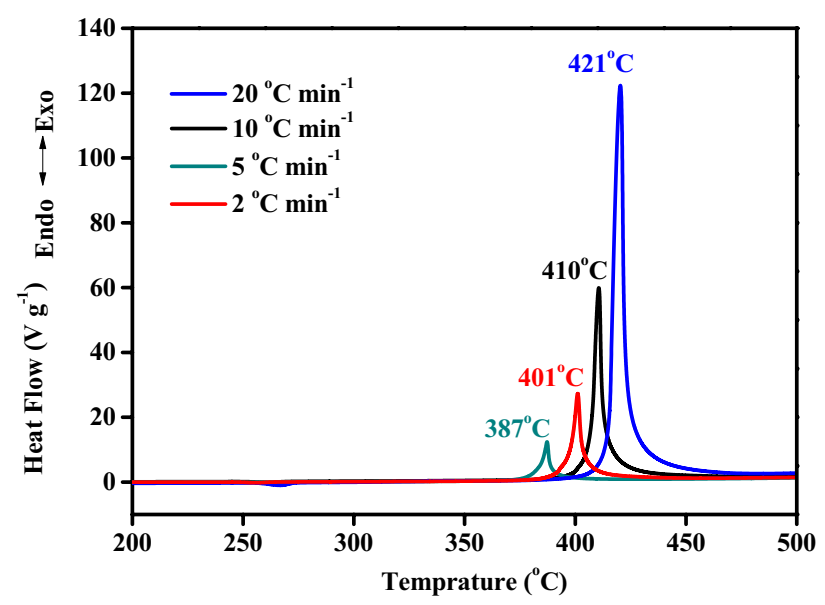

(b)

Figure 7. DSC measurements of $\mathrm{y}$-PTACOT (a) and z-TACOT (b) at the heating rates of 2, 5, 10 and $20{ }^{\circ} \mathrm{C} \mathrm{min}^{-1}$. 


\begin{tabular}{|l|l|l|l|l|}
\hline \multirow{2}{*}{$\boldsymbol{\beta}^{\mathbf{a}}\left({ }^{\circ} \mathbf{C} \mathbf{m i n}^{-1}\right)$} & \multicolumn{2}{l|}{$\mathbf{y}$-PTACOT } & \multicolumn{2}{l|}{-TACOT } \\
\cline { 2 - 5 } & $\mathbf{T}_{\mathbf{p}}{ }^{\mathbf{b}}(\mathbf{K})$ & $\Delta \mathbf{H}^{\mathbf{c}}(\mathbf{J} / \mathbf{g})$ & $\mathbf{T}_{\mathbf{p}} \mathbf{b}(\mathbf{K})$ & $\Delta \mathbf{H}^{\mathbf{c}}\left(\mathbf{J ~ g}^{-1}\right)$ \\
\hline 2 & 655 & 2767 & 660 & 2372 \\
\hline 5 & 670 & 2637 & 674 & 2394 \\
\hline 10 & 682 & 2651 & 683 & 2337 \\
\hline 20 & 693 & 2655 & 694 & 2369 \\
\hline
\end{tabular}

Table 1. Thermal decomposition parameters of $\mathrm{y}$-PTACOT and $\mathrm{z}$-TACOT. ${ }^{\mathrm{a}} \beta$, heating rate; ${ }^{\mathrm{b}} \mathrm{T}_{\mathrm{p}}$, peak temperature $(\mathrm{K}) ;{ }^{\mathrm{c}} \Delta \mathrm{H}$, decomposition heat.

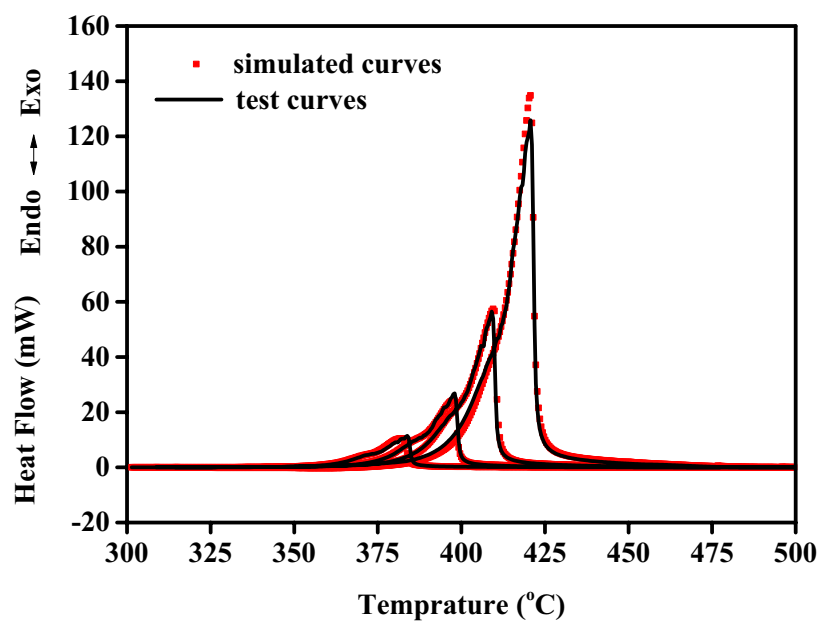

(a)

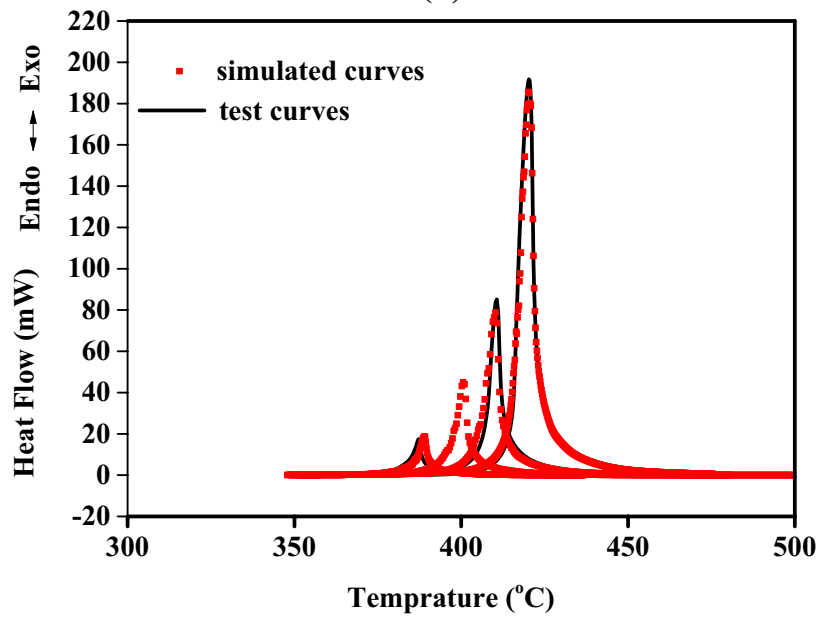

(b)

Figure 8. DSC measurements of $y$-PTACOT (a) and $z$-TACOT (b) at the heating rates of $2,5,10$ and $20{ }^{\circ} \mathrm{C} /$ $\min$.

rate while the decomposition heat was almost unchanged, further proved that these thermal decompositions are one-step reactions.

Calculation studies of the kinetic parameters and mechanism functions of the decomposition reaction of $y$-PTACOT and z-TACOT were carried out with NETZSCH Thermokinetics Software. Friedman method, a model-free algorithm, was first employed to predict the types of the decomposition reactions of y-PTACOT and $\mathrm{z}$-TACOT. The preliminary calculation results from Friedman method showed that both of the two decomposition reactions were acceleration processes. Meanwhile, based on the preliminary calculation results of apparent activation energies and pre-exponential constants, various reaction model algorithms were further applied for identifications of the reaction mechanisms. Multiple autocatalytic acceleration and nucleation reaction models were tested and proved that the decomposition reactions of y-PTACOT and z-TACOT agreed with nth order autocatalytic model $\left(C_{n}\right)$ and extended Prout-Tompkins model (BNA), respectively. Figure 8 showed the overlay 


\begin{tabular}{|l|l|l|l|}
\hline \multicolumn{4}{|l|}{ nth order autocatalytic model $\left(\mathbf{C}_{\mathbf{n}}\right)$} \\
\hline Activation Energy (Ea, kJ/mol) & LogA & React order $\mathbf{n}$ & Log(AutocatA) \\
\hline y-PTACOT & & & \\
\hline 226.164 & 14.690 & 0.393 & 1.148 \\
\hline Extended Prout-Tompkins model (BNA) \\
\hline Activation Energy (Ea, kJ/mol) & LogA & Autocat order & - \\
\hline z-TACOT & & & \\
\hline 262.930 & 19.197 & 1.107 & - \\
\hline
\end{tabular}

Table 2. Calculated thermal decomposition parameters of y-PTACOT and z-TACOT with mathematical models.

of fitted and measured curves and the results proved that prediction curves of y-PTACOT and z-TACOT coincided with their measurement results well. The kinetic parameters were summarized in Table 2 and the apparent activation energy of $z$-TACOT was higher than that of $y$-PTACOT, which may explain the better stability of $z$-TACOT.

To further study the mechanisms of the thermal decompositions of y-PTACOT and z-TACOT, the thermal decomposition of y-PTACOT and z-TACOT were then investigated through condensed-phase thermolysis/ Fourier-transform infrared (in-situ FTIR) spectroscopy method and their FTIR spectra at different temperatures are shown in Fig. 9. Figure $9 \mathrm{~b}$ showed that there was almost no structure change of y-PTACOT before $340{ }^{\circ} \mathrm{C}$. With the further increasing the heat temperature, the signals of tetraazapentalene structure started to weaken at $370{ }^{\circ} \mathrm{C}$ and weak peaks around $2350 \mathrm{~cm}^{-1}$ emerged and strengthened gradually. Signals of tetraazapentalene structure disappeared completely after $410^{\circ} \mathrm{C}$. The new signals around $2350 \mathrm{~cm}^{-1}$ may belong to the alkynyl moieties. Compared with tetraazapentalene structure, the dinitropyridine structure in $\mathrm{z}$-TACOT exhibited superior stability with much slower absorption peaks decrease rate which started from $370{ }^{\circ} \mathrm{C}$ and disappeared completely at $420{ }^{\circ} \mathrm{C}$ (Fig. 9d). Similar new signals around $2350 \mathrm{~cm}^{-1}$ were able to be observed at $390^{\circ} \mathrm{C}$. It is clear that both the arrangement of the inner salt backbones and the introduction of nitrogen atom have influence on the thermal decompositions of the corresponding energetic materials.

Simultaneous DSC-TG-FTIR-MS experiments were also performed for the investigation of the differences in evolved gases products (Fig. 10). Ion current curves of gaseous products of the thermal decompositions of y-PTACOT and z-TACOT were shown in Fig. 10a,b, respectively. Figure 10a showed the analysis result of the mass spectrum fragments of $\mathrm{y}$-PTACOT and the MS signals were found at $\mathrm{m} / \mathrm{z}$ values of $17,18,12,31,38,46$, $16,43,30$ and 44 at about $400{ }^{\circ} \mathrm{C}$, in order of ascending intensity. From elementary composition standpoint, the major fragments at $\mathrm{m} / \mathrm{z}$ values of $46,16,43,30$ and 44 correspond to $\mathrm{NO}_{2}, \mathrm{NH}_{2}, \mathrm{~N}_{3} \mathrm{H}$, NO and $\mathrm{CO}_{2}-\mathrm{N}_{2} \mathrm{O}$ fragments. The results were also supported by the absorption peaks from FTIR data (Figure S1). In the DSCTG-FTIR-MS experiments, the strong signals between 2200 and $2400 \mathrm{~cm}^{-1}$ belonged to $\mathrm{CO}_{2}$ and $\mathrm{N}_{2} \mathrm{O}$ while the signals between 1800 and $1950 \mathrm{~cm}^{-1}$ belonged to NO. It was also clear that the major fragments at $\mathrm{m} / \mathrm{z}$ values of 44 and 30 stated much earlier than the other fragments. Since the in-suit FTIR experiment had proved that the tetraazapentalene moieties decomposed prior to the dinitropyridine moieties, this result reflected the first appeared fragments were caused by the decomposition of " $y$-" tetraazapentalene structure. Interestingly, similar results were obtained by the analysis of ion current curves of gaseous products (Fig. 10b) and corresponding absorption peaks from the FTIR data in DSC-TG-FTIR-MS experiments (Figure S2) of z-TACOT, however, the fragments appeared at higher temperatures and in a much more concentrated way, which also agreed with the results from in-situ FTIR experiments (Fig. 9d).

From structural point of view, the poly-nitrogen core structures based on the poly-nitrogen core structures are thermally less stable parts in the structures of y-PTACOT and z-TACOT due to the thermal activity of polynitrogen species. Based on results of the in-situ FTIR and DSC-TG-FTIR-MS experiments, decomposition processes start from the tetraazapentalene moieties and the " $y$-" tetraazapentalene structure suffers from greater fragility. Calculation methods were carried out to check the bond orders of the " $y-$ " and " $z-$ " core structures, finding that the bond order of $\mathrm{N}_{4}-\mathrm{N}_{5}$ in " $\mathrm{y}$-" tetraazapentalene structure is only about 0.85 which are much lower than other bond orders in the poly-nitrogen core structures of " $y-$ " and " $z$-" poly-nitrogen core structures (Fig. 11a and Table S1, S2). The low bond order value of $\mathrm{N}_{4}-\mathrm{N}_{5}$ in " $\mathrm{y}$-" tetraazapentalene structure indicated the weak bond stability. On the basis of the above-described analytical and calculated results, we deduced plausible thermal decomposition mechanisms as illustrated in Fig. $11 \mathrm{~b}$.

\section{Conclusions}

Comparative research on the detailed thermal behaviors of y-PTACOT and z-TACOT, two energetic materials based on tetraazapentalene backbones with different arrangement, was carried out through experimental and calculation methods. The two inner salt structures exhibited similar thermal decomposition behaviors with much higher decomposition temperatures than those of most traditional energetic materials. The endothermic peak observed at about $260^{\circ} \mathrm{C}$ during the decomposition process of $\mathrm{z}$-TACOT was proved to be an irreversible physical change through MDSC measurements and a possible crystal transformation process was proposed. Calculation studies of the kinetic parameters and mechanism functions of the decomposition reaction of y-PTACOT and $\mathrm{z}$-TACOT showed that the decomposition reactions of $\mathrm{z}$-TACOT and y-PTACOT agreed with nth order 


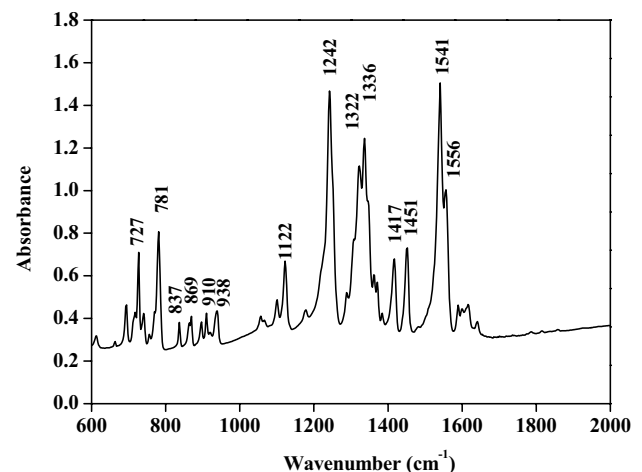

(a)

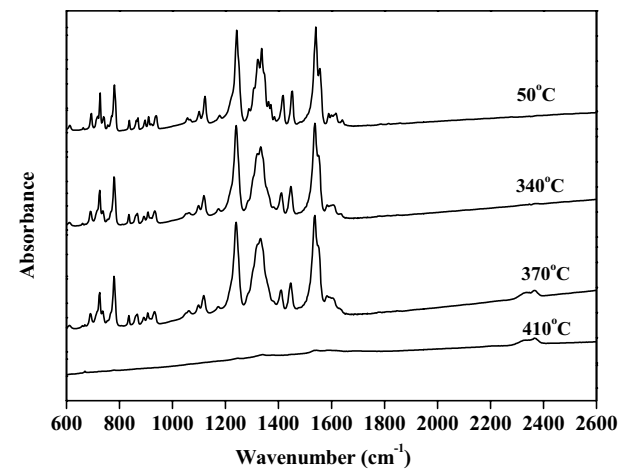

(b)

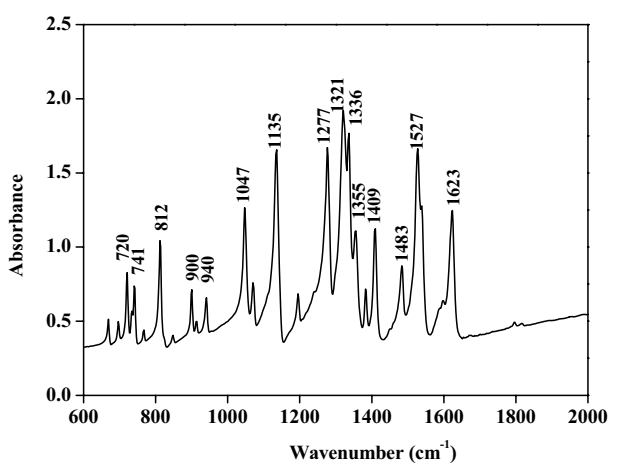

(c)

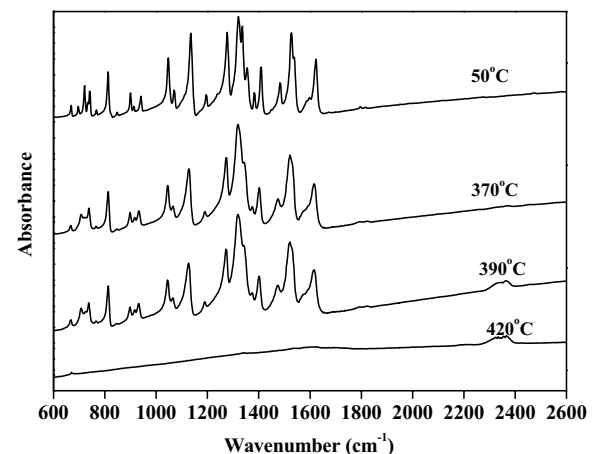

(d)

Figure 9. FTIR experiments of y-PTACOT and z-TACOT at room temperatures (a and $\mathbf{c}$ ) and high temperatures (b and $\mathbf{d})$. 
Ion Current / A

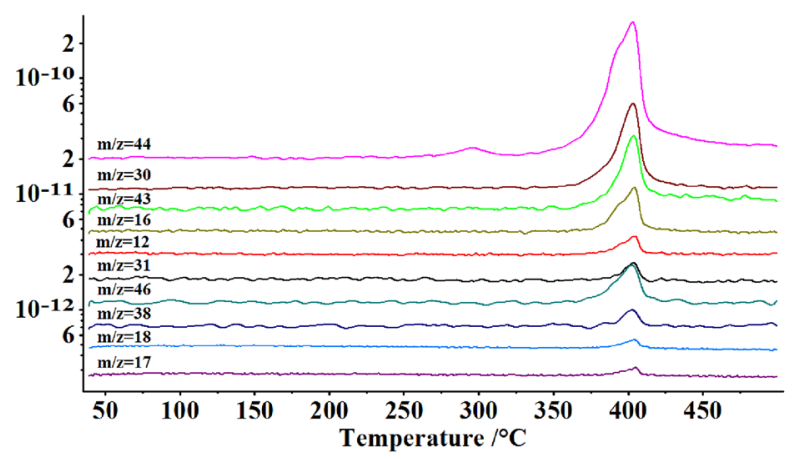

(a)

Ion Current/A

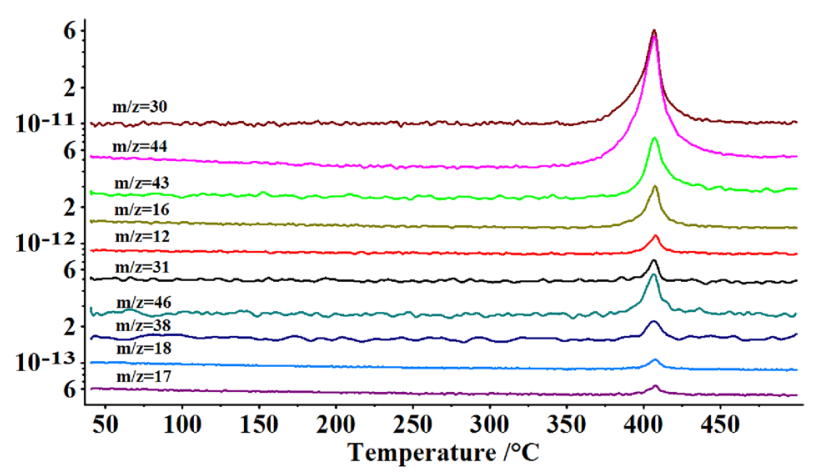

(b)

Figure 10. Ion current curves of gaseous products of the thermal decompositions of y-PTACOT (a) and z-TACOT (b) from simultaneous DSC-TG-FTIR-MS experiments.

autocatalytic model $\left(\mathrm{C}_{\mathrm{n}}\right)$ and extended Prout-Tompkins model (BNA), respectively. The apparent activation energy of $z$-TACOT was higher than that of $y$-PTACOT. Similar results were found from the DSC-TG-FTIR-MS experiments of $y$-PTACOT and $z$-TACOT, however, the fragments of $z$-TACOT appeared at higher temperatures and in a much more concentrated way. Compared with tetraazapentalene structure, the nitropyridine structure in y-PTACOT exhibited better stability with much slower absorption peaks decrease rate. In-suit FTIR experiment result of $z$-TACOT varied from that of $y$-PTACOT in which the signals of both tetraazapentalene and dinitrobenzene structures weakened almost synchronously. Obviously, the arrangement of the inner salt backbones has great influence on the thermal decompositions of the corresponding energetic materials.

\section{Methods}

The samples of $y$-PTACOT and $z$-TACOT were prepared according to the reported nitration methods ${ }^{20,21}$. Thermal analysis experiments were performed with differential scanning calorimetry (DSC) Q250 instrument (TA, America) and model TG-DSC STA 449F3 instrument (NETZSCH, Germany). Operation conditions: sample mass, $0.5 \mathrm{mg}$; atmosphere, dynamic nitrogen; aluminum cell. IR spectra was recorded on a Nicolet 60SX FTIR spectrometer with HgCdTe detector. Condensed-phase thermolysis/Fourier-transform infrared (in-situ FTIR) spectroscopy studies were carried out with Nicolet 60 SXR FTIR spectrometer. Operation conditions: sample

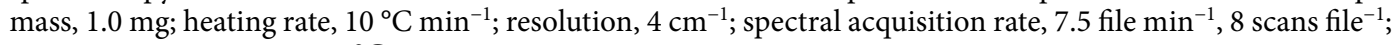
temperature range, $50-470^{\circ} \mathrm{C}$. 


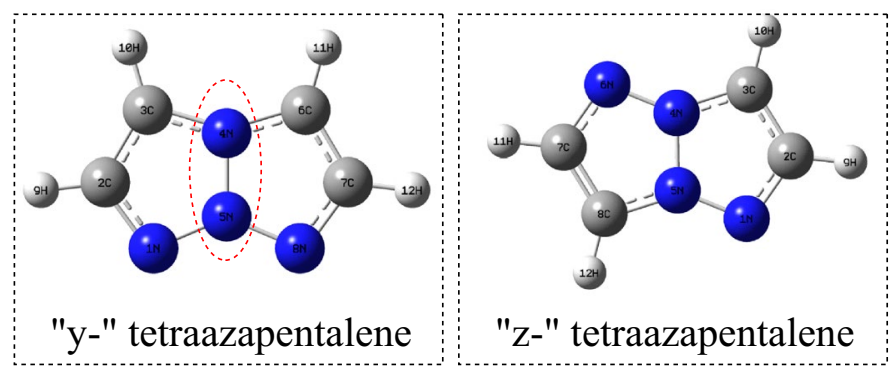

(a)
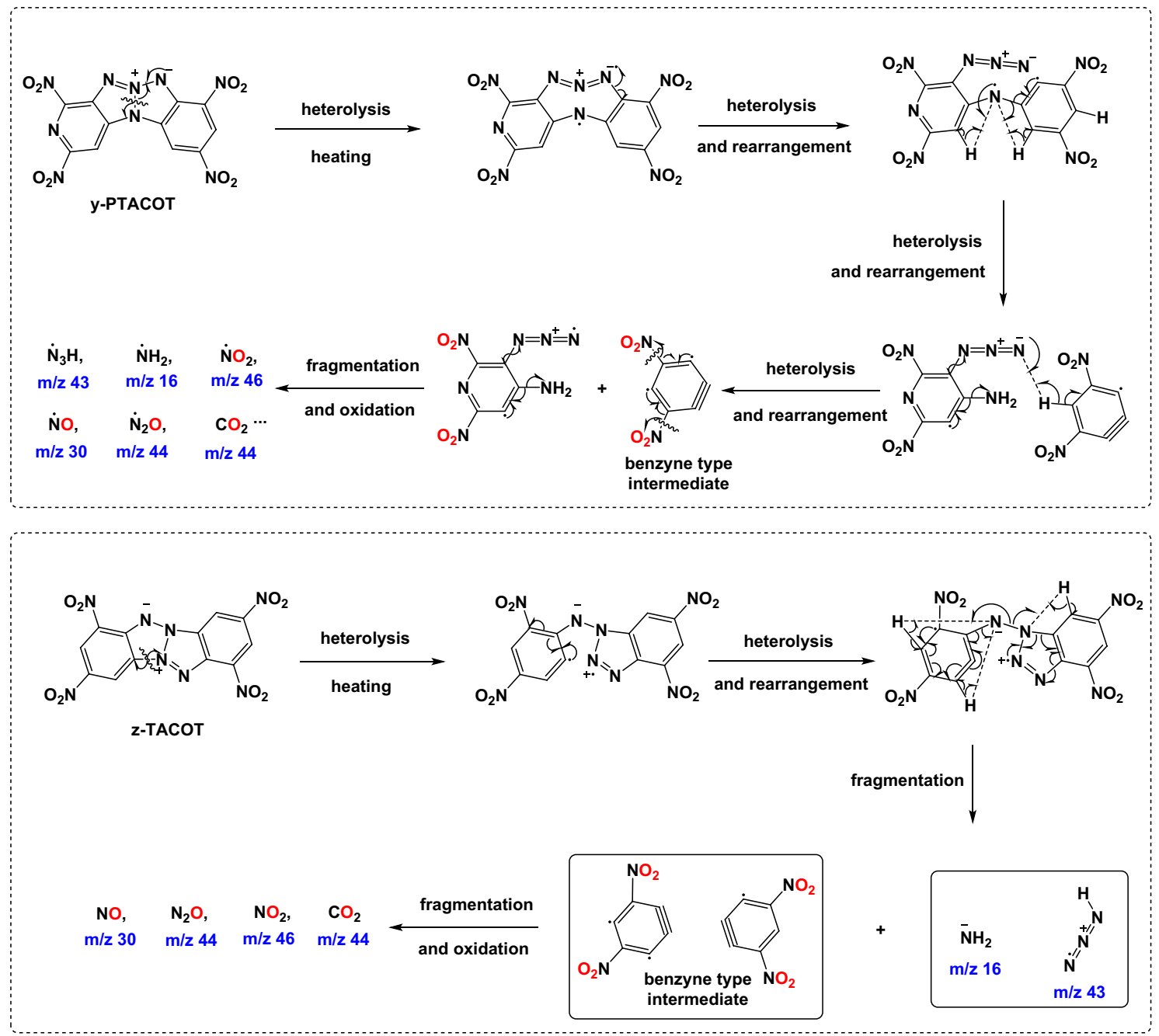

(b)

Figure 11. Proposed thermal decomposition mechanisms of y-PTACOT and z-TACOT.

\section{Data availability}

All data generated or analyzed during this study are included in this published article (and its Supplementary Information Files).

Received: 26 May 2020; Accepted: 30 November 2020

Published online: 10 December 2020

\section{References}

1. Yan, T. G. et al. 1,2,4-Oxadiazole-bridged polynitropyrazole energetic materials with enhanced thermal stability and low sensitivity. ChemPlusChem 84, 1567-1577 (2019).

2. Zhou, J. et al. Thermal studies of novel molecular perovskite energetic material $\left(\mathrm{C}_{6} \mathrm{H}_{14} \mathrm{~N}_{2}\right)\left[\mathrm{NH}_{4}\left(\mathrm{ClO}_{4}\right)_{3}\right]$. Chin. Chem. Lett. 31, 554-558 (2020). 
3. Bian, C. M. et al. 3-Nitro-1-(2H-tetrazol-5-yl)-1H-1,2,4-triazol-5-amine (HANTT) and its energetic salts: highly thermally stable energetic materials with low sensitivity. J. Mater. Chem. A 3, 163-169 (2015).

4. Yuan, W. et al. Super impact stable TATB explosives recrystallized by bicarbonate ionic liquids with a record solubility. Sci. Rep. 10, 4477 (2020).

5. Klapötke, T. M. et al. Thermal stabilization of energetic materials by the aromatic nitrogen-rich 4,4'5,5'-tetraamino-3,3'-bi-1,2,4triazolium cation. J. Mater. Chem. A 3, 2658-2668 (2015).

6. Zhang, J. Progress on synthesis of heat-resistant aromatic energetic compounds. Chin. J. Energ. Mater. 25, 873-880 (2017).

7. Zhang, W. Q. et al. A promising high-energy-density material. Nat. Commun. 8, 1-7 (2017).

8. Zhou, J. et al. Research on the thermal behavior of novel heat resistance explosive 5,5'-bis(2,4,6-trinitrophenyl)-2,2'-bi(1,3,4oxadiazole). J. Anal. Appl. Pyrol. 129, 189-194 (2018).

9. Agrawal, J. P. Past, present \& future of thermally stable explosives. Cent. Eur. J. Energ. Mat. 9, 273-290 (2012).

10. Shipp, K. G. Reactions of $\alpha$-substituted polynitrotoluenes. I. synthesis of 2,2',4,4,6,6'-hexanitrostilbene. J. Org. Chem. 29, 2620-2623 (1964).

11. Klapötke, T. M. et al. Synthesis and investigation of 2,6-bis(picrylamino)-3,5-dinitro-pyridine (PYX) and its salts. Chem. Eur. J. 22, 8619-8626 (2016).

12. Ott, D. G. et al. Preparation of 1,3,5-triamino-2,4,6-trinitrobenzene from3,5-dichloroanisole. J. Energ. Mater. 5, 343-354 (1987).

13. Xu, W. Z. et al. Preparation and properties of an insensitive booster explosive based on LLM-105. Propell. Explos. Pyrot. 38, 136-141 (2013).

14. Coburn, M. D. Picrylamino-substituted heterocycles. III. 1,2,4-triazoles. J. Heterocycl. Chem. 5, 199-203 (1968).

15. Cui, J. H. et al. Study on the crystal structure and hygroscopicity of ammonium dinitramide. J. Chem. Eng. Data. 55, 3229-3234 (2010).

16. Kohga, M. Preparation of combined ammonium perchlorate/ammonium nitrate samples by freeze drying. J. Energ. Mat. 35, 1-16 (2016).

17. Carboni, R. A. Tetracyanoethylene//Organic Syntheses (American Cancer Society, New York, 2003).

18. Yang, X. M. TACOT-derived new nitrogen rich energetic compounds: synthesis, characterization and properties. New J. Chem. 43, 19180-19185 (2019).

19. Yang, F. et al. Studies on the thermal behavior and safety of a novel thermostable explosive BPTAP. RSC Adv. 9, 22198-22204 (2019).

20. Carboni, R. A. et al. Aromatic azapentalenes. I. dibenzo-1,3a,4,6a-tetraazapentalene and dibenzo-1,3a,6,6a-tetraazapentalene. New heteroaromatic systems. J. Am. Chem. Soc. 89, 2618-2625 (1967).

21. Balachari, D. et al. Synthesis of new dipyridotetraazapentalenes. Tetrahedron Lett. 38, 8607-8610 (1997).

22. Subramanian, G. et al. Synthesis of benzotriazolo[1,2-a]benzotriazole derivatives as new high density, insensitive energetic materials. J. Org. Chem. 61, 5801-5803 (1996).

23. Subramanian, G. et al. Reactions of benzotriazolo[2,1-a]benzotriazole derivatives. 1. Synthesis of new insensitive high-density energetic compounds. J. Org. Chem. 60, 6110-6113 (1995).

24. Liu, R. et al. A study of the melting process of NC by thermal analysis. Chin. J. Energ. Mater. 6, 112-117 (1998).

\section{Acknowledgements}

We are grateful to the financial support from National Natural Science Foundation of China (No. 21805226, No. 21805223), the China Postdoctoral Science Foundation (No. 2018M633552) and the China Scholarship Council (No. 201805290006).

\section{Author contributions}

J.Z. performed most of the experiments; L.D. designed the study; B.-Z.W. and J.-L.Z. conceived the experiments and wrote the main manuscript text; Y.Z. and X.-Z.L. analyzed the results. All authors reviewed the manuscript.

\section{Competing interests}

The authors declare no competing interests.

\section{Additional information}

Supplementary information The online version contains supplementary material available at https://doi. org/10.1038/s41598-020-78980-1.

Correspondence and requests for materials should be addressed to L.D., B.W. or J.Z.

Reprints and permissions information is available at www.nature.com/reprints.

Publisher's note Springer Nature remains neutral with regard to jurisdictional claims in published maps and institutional affiliations.

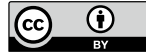

Open Access This article is licensed under a Creative Commons Attribution 4.0 International License, which permits use, sharing, adaptation, distribution and reproduction in any medium or format, as long as you give appropriate credit to the original author(s) and the source, provide a link to the Creative Commons licence, and indicate if changes were made. The images or other third party material in this article are included in the article's Creative Commons licence, unless indicated otherwise in a credit line to the material. If material is not included in the article's Creative Commons licence and your intended use is not permitted by statutory regulation or exceeds the permitted use, you will need to obtain permission directly from the copyright holder. To view a copy of this licence, visit http://creativecommons.org/licenses/by/4.0/.

(C) The Author(s) 2020 